TITLE:

\title{
Mechanism of the slow-moving landslides in Jurassic red-strata in the Three Gorges Reservoir, China
}

AUTHOR(S):

Miao, Haibo; Wang, Gonghui; Yin, Kunlong; Kamai, Toshitaka; Li, Yuanyao

\section{CITATION:}

Miao, Haibo ...[et al]. Mechanism of the slow-moving landslides in Jurassic red-strata in the Three Gorges Reservoir, China. Engineering Geology 2014, 171: 59-69

\section{ISSUE DATE:}

2014-03

URL:

http://hdl.handle.net/2433/182050

\section{RIGHT:}

(C) 2014 Elsevier B.V.; This is not the published version. Please cite only the published version.; この論文は出版社版でありません。引用の際に は出版社版をご確認ご利用ください。 
Mechanism of the slow-moving landslides in Jurassic red-strata in the Three Gorges

Abstract:

6 Landslides in Jurassic red-strata make up a great part of geohazards in the Three Gorges

7 Reservoir (TGR) in China. Most of them begin to move slowly with the accumulated

8 displacement increasing stepwise, which corresponds to seasonal rainfall and 30 meters of

9 reservoir water level fluctuation ( $145 \mathrm{~m}$ to $175 \mathrm{~m}$ on elevation). We analyzed the movement

10 of 21 slow moving landslides in Jurassic red-strata in TGR, and found that all these

11 landslides involved in two differing processes; one is the sliding process with different

12 shear speeds of soils within the sliding zone (landslide activity), and the other one is in

13 steady state with different durations (dormant state). This means that the soil within the

14 sliding surface may experience shearing at different shear rates and recovery in shear

15 strength during the dormant period. To clarify the mechanism of this kind of movement, we

16 took soil samples from the sliding surface of Xiangshanlu landslide, which occurred on

17 August 30, 2008 in Jurassic red-strata in TGR, and examined the shear rate dependency and

18 recovery of shear resistance by means of ring shear tests. The results of tests at different

19 shear rates show that the shear strength is positively dependent on the shear rate, and can be

20 recovered within short consolidation duration after the shearing ceased. By increasing the

21 pore-water pressure (PWP) from the upper layer of the sample, we also examined the 
22 initiation of shearing which can simulate the restart of landsliding due to the fluctuation of

23 groundwater level caused by rainfall or changes in reservoir water level. The monitored

24 PWP near the sliding surface revealed that there was delayed response of PWP near the

25 sliding surface to the applied one. This kind of delayed response in pore-water pressure may

26 provide help for the prediction of landslide occurrence due to rainfall or fluctuation of reservoir water level.

29 Keywords: landslides; the Three Gorges Reservoir; Jurassic red-strata; slow movement;

30 shear resistance; shear rate effect 


\section{Introduction}

The Three Gorges Reservoir in China (hereinafter we call TGR, its location is shown in Fig. 1) is an area with a large number of landslides (Chen, 1999; Deng et al., 2000; Wu et al., 2001; Li, 2002; Liu, et al., 2004; Wen et al., 2007; Jian et al., 2009; Li et al., 2013, among others). These landslides developed in all strata, especially in Jurassic stratum. The Jurassic lithology in TGR is continental lake facies sedimentary rocks, the colors of which are mainly fuchsia, maroon, or red brown; therefore, the Jurassic stratum is often called "red-strata" by Chinese academe (Li et al., 2002; Chen et al., 2004; Xu et al, 2010). From the lithology structure of Jurassic red-strata in TGR, the interbedding layer of thick silty-sandstone and thin sandy-mudstone is an important reason for the development of weak bands with high content of clay mineral like montmorillonite and illite in the long geological history (Jian et al., 2005, 2008), which caused some typical landslides, such as Chonggang landslide (Yin et al., 1993), four landslide groups in Wanzhou area (Jian et al., 2009), Jipazi landslide (Huang, 2007), Qianjiangping landslide (Wang, et al., 2004; Liao et al, 2005) and so on. It has been reported that among the landslides selected in the second and the third phase of mitigating and monitoring projects in TGR supported by Chinese government, more than $70 \%$ are in Jurassic red-strata (Chai et al., 2009). Up to now, many studies had been performed on the landslides occurring in Jurassic red-strata in the TGR area with focus on examining the geological basis (say, possible clay mineral in the weak bands of potential sliding surface). However, the mechanism of the movement in the 
51 pre-failure stage, especially in the case of slow movement of landslides influenced by seasonal rainfall and periodic reservoir water level fluctuation, is not yet well understood.

In this paper, we investigate the movements of 21 landslides in the Jurassic red-strata in TGR and examined the moving types of these landslides. The ring shear apparatus developed by Disaster Prevention Research Institute, Kyoto University, was used to simulate the shear process of the soils within the sliding zone in the slow movement through the case study of a landslide occurred on August 30, 2008, in Jurassic red-strata in TGR. We performed three groups of tests, i.e., test with different shear rates, test with different consolidation duration and, tests with changing the pore-water pressure of shear band. Based on the results, three aspects such as shear rate effect, recovery of residual shear strength and trigger of landslide reactivation, are discussed to reveal the mechanism of the slow movement of the landslides in Jurassic red-strata in the Three Gorges Reservoir.

\section{Type of the slow movement}

To reduce the risk from landslides in TGR, Chinese government approved many projects which involve systematic investigation of landslides and potentially unstable slopes, ancient landslides reactivation and their failure mechanism, especially the monitoring of large landslides (Wen et al., 2007). In many cases the surface monitoring data are much easier to be obtained through using a wide range of techniques such as survey markers, extensometers, and digital photogrammetry, as well as global position system (GPS) and interferometric synthetic aperture radar (InSAR). As a result, in the monitoring of these large landslides in 
TGR, GPS measurements which can provide the surface displacements have been widely used. Petley et al. $(2002,2005)$ demonstrated that the patterns of landslide movement provide an insight into the processes occurring in the sliding zone, and used the surface monitoring data to interpret landslide movement patterns, which mainly includes four types: (1) very slow or creep movement, which occurs at the moment of formation of the tension area located on the crown or flanks of the landslide; (2) low velocity movements, caused by gradual formation of the shear surface; (3) rapid movement because of the sliding mass disaggregating into loose materials; (4) very rapid movement as a result of landside fails.

In this study 21 landslides monitored by GPS in Jurassic red-strata in TGR were examined. In each landslide, 2-9 GPS stations were installed according to its scale. We obtained the accumulated displacements of monitoring points from January 2007 to November 2009 (35 months). We studied the monitoring point with the largest accumulated displacement for each landslide, and plotted 21 curves as showed in Fig. 2. These curves can be divided into two groups (Figs. 2a, b) according to the displacements. In Fig. 2a, 15 curves of accumulated displacement versus time display "random oscillation" or "trending oscillation" with an average sliding rate $<6 \mathrm{~cm} /$ year. These oscillations in the accumulated displacement might result from the measurement errors that are normally intensive in the tiny data range (Ueno et al., 2003). Other 6 landslides (Fig. 2b) had their displacements increased mainly stepwise with their sliding rates greater than $6 \mathrm{~cm} /$ year but smaller than $1.5 \mathrm{~m} / \mathrm{year}$. For the first group, all the landslides were in very slow movement or creep movement, which could be classified as the first style of the movement of rotational and translational landslides 

stop and keep staying at the dormant state? along existing sliding surface.. slow movement according to the sliding rate proposed by Schuster \& Krizek (1978). Because all GPS stations in each landslide were installed soon after cracks occurred in the walls of houses locating on the slope, following the interpretation by Petley et al. (2005), we inferred that the movement shown in Fig. 2a mainly resulted from the crack propagation (shear surface generation), whereas the slow movement (Fig. 2b) resulted from the occurrence of movement

Irrespective of the differences in the accumulated displacement, all the displacements showing slow movement (Fig. 2b) increased stepwise, which can by conceptually illustrated by a model shown in Fig. 3a. Differentiating this stepwise displacement gives an increasing or decreasing displacement rate, indicating that the landslide would experience alternations of accelerating and decelerating movements (Fig. 3b). Therefore, it is expected that the soils within the sliding zone would undergo two processes; one is shearing at differing shear rates, and the other one is recovery of shear strength under a constant normal stress with different duration. These two processes correspond to the sliding and dormant periods, respectively. Therefore, in order to understand the mechanism of the slow-moving landslides in Jurassic red-strata in TGR, two questions should be answered: (1) how does the landslide come into reactivation from dormant state as shown conceptually in Fig. 3; (2) how does the movement

\section{$113 \quad 3$ Ring shear test}




\subsection{Testing sample}

To reveal the mechanism of these slowly moving landslides in Jurassic red-strata in the TGR, we took soil samples along the sliding surface from Xiangshanlu landslide, which occurred in the early morning on August 30, 2008. This landslide is located on the left bank of Tongguluo River, a tributary of the Yangtze River in Shazhenxi Town, Zigui country in

119 TGR (Fig. 4). The landslide covers an area of $3.3 \times 10^{4} \mathrm{~m}^{2}$ and has a volume of $0.165 \times 10^{6} \mathrm{~m}^{3}$.

120 The sliding mass was composed of Quaternary colluvium and eluvium, and the lithology of

121 sliding bed rock is middle Jurassic Qianfoyan Formation $\left(\mathrm{J}_{2} \mathrm{q}\right)$, as well as the soils along the

122 sliding surface are silty clay with the thickness of $10 \mathrm{~cm}$, formed by weathering of mudstone and sandy-mudstone (Fig. 5). It is noted that we also took samples from boring cores taken

124 from differing landslides shown in Fig. 2b, but the volumes of the cores near the sliding 125 surface were not enough for the performance of ring shear tests. We compared the physical 126 properties (see, Table 1) of these core samples to those of Xiangshanlu landslide, and found 127 that they are basically the same. Therefore, in the following we only conducted ring shear 128 tests on the samples taken from Xiangshanlu landslide as an example.

129 The testing sample is remolded from soils within the sliding zone, which mainly consists

130 of silt (about $92 \%$ ) with $30 \%$ clay. The grain size distribution of the sample is presented in

131 Fig. 6a. Some physical property indexes such as dry density, liquid limit, plastic limit,

132 plasticity index and uniformity coefficient, as well as the coefficient of curvature, are listed in

133 Table 1. The plasticity chart is showed in Fig. 6b. In result, the testing sample (hereinafter we 134 call this sample as XSL) is low liquid limit silty clay. 


\subsection{Ring shear apparatus}

137 Ring shear apparatus has been widely used in examining the shear behavior of the soil with

138 large shear displacement and the residual shear strength for the analysis of slope stability

139 (Bishop et al., 1971; Bromhead, 1979; Hungr and Morgenstern, 1984; Stark and Contreras,

140 1996; Wang and Sassa, 2002; Sassa et al., 2004; Wang et al., 2007, 2010; Sadrekarimi and

141 Olson, 2009). The ring shear apparatus used in the present research is DPRI-4 with the shear

142 area of $314.16 \mathrm{~cm}^{2}$, which was developed in Disaster Prevention Research Institute at Kyoto

143 University, Japan (Sassa et al., 2004). This apparatus enables the simulation of many different

144 kinds of static and dynamic loading under drained or undrained conditions. The samples can

145 be sheared by means of torque-controlled or shear speed-controlled method (Wang and Sassa,

146 2002; Sassa et al., 2003).

\subsection{Testing procedure}

149 The testing procedure consisted of three parts: sample preparation, consolidation and

150 shearing. During the sample preparation, distilled water was firstly added to the oven dried

151 sample to elevate the initial water content close to its plastic limit, and then the sample was

152 stirred evenly. After keeping the sample for 72 hours in a sealed container to ensure the

153 uniform distribution of moisture, the sample was placed into the shear box. After the

154 placement of the sample and the set-up of shear system, we measured the friction between the

155 upper pair of rings and the rubber edges at the adjusted gap value for the employed ring shear 
156 apparatus. This measured friction was then subtracted from the measured shear resistance to

157 obtain the real shear strength of the sample (Sassa et al., 2003, 2004).

158 After the measurement of friction of rubber edges, the sample was normally consolidated

159 under a normal stress of $98 \mathrm{kPa}$ without applying any shear stress. It is noted that we planned

160 to shear the sample at differing normal stress levels. However, here, we used $98 \mathrm{kPa}$ as the

161 first normal stress level, just because the ring shear apparatus was designed for tests under

162 higher normal stress (up to $2 \mathrm{MPa}$ ), and servo control system does not enable better

163 performance if the applied normal stress is too small, say, less than $50 \mathrm{kPa}$.

164 After consolidation under the normal stress of $98 \mathrm{kPa}$ was finished (evidenced by no

165 further change in sample volume), we sheared the sample drained at a shear rate of 0.0011

$166 \mathrm{~mm} / \mathrm{s}$ to measure the residual shear strength. Using the same method, we measured the

167 residual shear strength at three differing normal stress levels $(98,147$, and $196 \mathrm{kPa})$. We also

168 examined the shear rate dependency of residual shear strength by shearing the same sample at

169 differing shear rates while keeping the normal stress constant (196 kPa). We further examined

170 the effect of consolidation duration on the strength recovery. After the shear test with the

171 normal stress of $196 \mathrm{kPa}$ was finished, the sample was kept in consolidation with the same

172 normal stress, for 1 day, 3 days, 5 days and 17 days, respectively. At the end of each

173 consolidation process, the sample was sheared with the same shear rate under the same

174 normal stress. Finally, after the above mentioned tests were finished, we consolidated the

175 sample for 14 days under the normal stress of $196 \mathrm{kPa}$ and shear stress of $40 \mathrm{kPa}$

176 (corresponding to a slope angle of 11.5 degrees), and then applied a pore-water pressure of 80 
$177 \mathrm{kPa}$ from the upper drainage tube to check the possible response of pore water pressure within 178 the shear zone.

\section{Testing results}

181

182

183

\subsection{Basic shear behavior of tested soils}

The shear behavior and residual shear strength of XSL sample were obtained. Figure 7a shows the normal stress, shear resistance and pore-water pressure (PWP) against the shear displacement for the test under the normal stress of $98 \mathrm{kPa}$. At the beginning of shearing (the shear displacement $<4 \mathrm{~mm}$ ), the PWP increased almost linearly with shear displacement, thereafter it decreased slowly with progress of shearing, and the shear resistance increased correspondingly. Because this test was performed under drained condition, we inferred that the monitored PWP resulted from the unbalance between the generation and dissipation rates of PWP. In the first shearing stage (say within $4 \mathrm{~mm}$ of shear displacement), PWP generation rate might be greater than the dissipation rate due to the reduction in porosity of soil layers near the sliding surface. This would result in the buildup of excess PWP. It is noted that a vertical displacement of about $0.3 \mathrm{~mm}$ was observed within the first $4 \mathrm{~mm}$ of shear displacement (called dilation, see, Pudasaini and Hutter, 2007). With further progress of shearing, PWP generation rate would become smaller than the dissipation rate, and then the excess PWP would become smaller.

The residual shear strengths obtained under three differing normal stresses are plotted in Fig. $7 \mathrm{~b}$ against the effective normal stresses. The line (residual failure line) bonding these 
198 three points has a y-intercept of $18 \mathrm{kPa}$ and a slope angle of 13 degrees. According to the

199 Mohr-Coulomb criterion, the effective residual cohesion of the tested sample is $18 \mathrm{kPa}$ and

200 the effective residual internal friction angle is 13 degrees.

\subsection{Shear rate effect}

According to the movement features summarized in Fig. 2, these landslides in Jurassic red-strata in TGR have different moving speeds in different active stage. This means that the soil layer within the shear zone may suffer from differing rates of shearing. To clarify the possible effects of shear rates on the shear behavior and then on the landsliding, we sheared the sample to residual state at different shear rates under drained condition, and in each test 208 we kept the normal stress constant $(196 \mathrm{kPa})$.

We performed multistage testing, which has been found to produce results similar to

210 testing of individual samples (Bromhead, 1992; Tika et al., 1996; Harris and Watson, 1997;

211 Tiwari and Marui, 2004; Suzuki et al., 2004). At first, we sheared the sample at a 212 displacement rate of $0.001135 \mathrm{~mm} / \mathrm{s}$ (the lowest rate available by the ring shear apparatus 213 employed in this study) to the residual state, and then elevated the rate to a differing one to 214 measure the residual shear strength at this new shear rate. With the same test process, we 215 sheared the sample at 13 different displacement rates.

216 The results of the tests performed at different shear rates are presented in Fig. 8 which 217 plots the shear resistance at each shear displacement rate. As shown in Fig. 8, the shear 218 resistance became greater with increase of shear displacement rate, and the fitted curve of all 
219 the data points presents a growth-oriented power function. The residual shear resistance at the 220 shear displacement rate of $175.56 \mathrm{~mm} / \mathrm{s}(115.4 \mathrm{kPa})$ was approximately twice that obtained at 221 the shear displacement rate of $0.0011 \mathrm{~mm} / \mathrm{s}(58.2 \mathrm{kPa})$, indicating that the shear strength is strongly dependent on the shear displacement rate.

\subsection{Recovery of shear strength with consolidation period}

When landslides reach the dormant state, the shear strength could be recovered (Gibo et al., 2002; Nakamura, 2002; Carrubba \& Del Fabbro, 2008), and it is expected that the recovered shear strength is time dependent. As shown in Fig. 2, these landslides experienced the dormant state with different periods. Therefore, it is expected that the shear strength would be recovered in some extent. In order to understand the recovery of shear strength of soils within sliding zone after different consolidation durations, we performed ring shear test 231 on the sample with different consolidation durations.

Acknowledging that the residual shear strength of clayey soils has no association with the

233 initial structure and stress history of the soil (Mitchell, 1976), after the tests using differing

234 shear displacement rates, we kept the soil sample in consolidation for 1 day, 3 days, 5 days 235 and 17 days respectively under the normal stress of $196 \mathrm{kPa}$ (hereinafter, we call them as test TC1, TC3, TC5 and TC17, respectively). At the end of each consolidation process we sheared

237 the sample at the same shear displacement rate of $0.0077 \mathrm{~mm} / \mathrm{s}$.

238 The measured shear resistance and vertical displacement are plotted in Figs. 9a, b, 239 respectively, against the shear displacement. From Fig. 9a, we find that the peak shear 
240 strengths obtained from TC5 was greater than that of TC3 and also both of them were greater

241 than that of TC1. This indicates that the shear strength could be recovered with consolidation

242 period. However, with further increase of the consolidation period, the recovery in the peak

243 shear strength is small, which can be seen from the test results from TC17. It is also noted that

244 the shear strengths at the shear displacement of $250 \mathrm{~mm}$ were different for these four tests,

245 probably due to volume change in the sample with progress of shearing. It has been clarified

246 that a shear zone will be formed and become thicker with progress of shearing (shear included

247 dilation, see, e.g., Pudasaini and Hutter, 2007) in ring shear tests on sandy soils (Wang and

248 Sassa, 2002; Wang et al., 2007; Wang et al., 2010). If the sandy soils were in loose state after

249 the consolidation, the shear zone will become denser. This is evidenced by the monitored

250 vertical displacement shown in Fig. 9b, where the vertical displacement became a bit greater

251 with progress of shear time. Re-shearing the denser shear zone will result in greater peak

252 shear strength, but should not result in any difference in the residual shear strength. Therefore,

253 we inferred that these differences in the shear strength at the shear displacement of $250 \mathrm{~mm}$

254 resulted from the fact that the shear did not reach the real residual shear state yet. From Fig.

2559 a, we conclude that the shear strength could be recovered in short period, say less than 5

256 days. Considering the main purpose of these tests is examining the possible strength regain

257 through comparing the peak shear strength, here we won't make further discussion on the

258 relationship between the formation of shear zone and residual shear strength. 
261 As well known, reservoir landslide is normally influenced by periodic fluctuation of

262 reservoir water level and/or seasonal rainfall. Groundwater table or pore-water pressure

263 within the soil layers of the landslide will be changed due to the fluctuation of reservoir water

264 level and/or precipitation. This kind of change will result in the decrease of effective normal

265 stress that causes the decrease of shear strength of soils within the sliding zone. To examine

266 the possible response of pore-water pressure of the soils near the sliding surface in the field to

267 this kind of variation of reservoir water level or groundwater table, we performed ring shear

268 test to examine the possible response of pore water pressure near the shear zone of specimen

269 to the change of pore-water pressure outside of the specimen.

After the above-mentioned test TC17 was finished, we changed the shear model from

271 shear-speed control to shear-stress control one. Using this shear-stress control model, we

272 consolidated the sample under a stress state with the normal stress being $196 \mathrm{kPa}$ and shear

273 stress being $40 \mathrm{kPa}$. After the consolidation, we applied a water pressure of $80 \mathrm{kPa}$ from the

274 upper part of the specimen by using another ring shear apparatus through a plastic pipe (Fig.

275 10). As shown in Fig. 10b, firstly we put the water into shear box of the left ring shear

276 apparatus and then applied a normal stress of $80 \mathrm{kPa}$ on the water. The applied water pressure

277 will load soon on the upper part of the sample in the ring shear box.

278 The monitored pore water pressure near the shear band (sliding surface) is plotted in Fig.

279 11a together with the applied normal stress, applied shear stress, shear displacement, and

280 effective normal stress. It is seen that the pore water pressure gradually elevated. Dissipating

281 of water pressure from the top of the sample to the shear band took approximately 6,000 
282

283

284

285

286

287

288

289

290

291

292

293

seconds. Thereafter, the pore-water pressure started to increase gradually. Figure $11 \mathrm{~b}$ presents the effective stress path together with the residual shear strength envelop (RSSE). With the increasing of pore-water pressure near the shear band, the effective normal stress gradually moved leftward to the RSSE. However, this moving process took a long time, because of the small initial applied stress $(40 \mathrm{kPa})$, and also probably due to the lower permeability of the sample. About 95,000 seconds later (26 hours and 40 minutes), we increased the shear stress artificially loaded on the shear band from $40 \mathrm{kPa}$ to $70 \mathrm{kPa}$, and then shear failure occurred with a continuously increased shear displacement (after point 'Failure', marked with an ellipse in Fig. 11b). According to Fig. 11b, it is expected that if the shear stress was increased to $54 \mathrm{kPa}$, shear failure would be triggered. However, after 14 days of consolidation the residual shear strength of the sample had a certain recovery (about $16 \mathrm{kPa}$ ). As the result, a shear stress greater than the residual shear strength will be needed to trigger the shear failure or reactivate the landsliding.

In addition, from this ring shear test we found a delayed response of pore water pressure within the soil layer near the sliding surface to the applied pore pressure. This delayed response follows the principle of pressure diffusion in soils, which has been used to study the rainfall-induced landslides (Haneberg, 1991; Reid, 1994), reservoir-induced seismicity (Talwani and Acree, 1984) and also landslide movement triggered by atmospheric tides (Schulz et al., 2009a).

For the landslide triggered by rainfall and/or reservoir water level fluctuation, the variable pore pressure will be applied on the sliding mass above the shear surface. In this condition, 
303 the diffusion of the pore pressure will occur, and then result in the change of pore water 304 pressure in the shear band. However, this change in the shear band will take a certain time 305 that is determined by the hydraulic diffusivity of the soils of sliding mass above the shear 306 band. In other words, there will be a delayed response of landsliding to rainfall and/or 307 fluctuation of reservoir water level.

\section{Discussion}

\subsection{Shear speed effect and residual shear strength recovery}

The effect of shear speed on the shear behavior of natural soils is complex. Lupini

312 (1980) and Lupini et al. (1981) firstly investigated the influence of shear speed on the

313 residual shear strength. Martins (1982), Skempton (1985), Lemos et al. (1985), Lemos

314 (1986), Tika (1989), and Tika et al. (1996) carried out further studies to examine the effect

315 of shear rate on the residual shear strength of differing types of soils.

Skempton (1985) showed that in slow shearing at the rate within $0.01 \mathrm{~mm} / \mathrm{min}$, the

317 variation of shear rate had tiny effect on the residual shear strength, while for the shear rate

318 larger than $100 \mathrm{~mm} / \mathrm{min}$ the effect was significant, which was related to clay fraction of the

319 soils. Lemos et al. (1985) proposed three types of variation of the residual strength with an

320 increasing rate of displacement, i.e. positive, neutral, and negative rate effect. Lupini (1981)

321 recognized three modes of residual shearing of cohesive soils, which is turbulent mode,

322 transitional mode and sliding mode. The mechanism was confirmed as proportions of platy 
323 particles to rotund particles present in the soil and the coefficient of inter particle friction of

324 the platy particles. The similar conclusions were also summarized by Tika et al. (1996).

325 According to Fig. 8, the role of positive shear rate effect on the residual shear strength

326 in the slow movement of landslides in Jurassic red-strata in the TGR can be explained as

327 follows. Firstly, when the landslide is trigged, the displacement rate increases because of the

328 initial positive acceleration. Secondly, due to the positive shear rate effect, the residual

329 shear strength becomes greater. As a result, the displacement rate increases to a maximum

330 value until the positive acceleration reduces to zero. Thirdly, when the residual shear

331 resistance at the maximum shear speed is larger than sliding force, deceleration appears

332 which results in the decrease in displacement rate with the reduction in residual shear

333 strength. Finally the deceleration reduces to zero and the landslide movement stops.

334 From the movement features summarized in Fig. $2 b$ and the conceptual model

335 illustrated in Fig. 3, it is expected that the landslide would enter into a dormant state after a

336 certain period of decelerating movement. It is well known that for a landslide with

337 pre-existing shear zone, the shear strength of the soils within the sliding zone will be in

338 residual state when the landslide is in dormant stage, and will gain a certain recovery when

339 the landslide enters the dormant state (Ren et al., 1996; Gibo et al., 2002; Nakamura, 2002).

340 As shown in Fig. 9, the residual shear strength of the tested sample revealed a fast recovery,

341 indicating that once the landslide entered the dormant state, shear resistance increased and

342 then additional force (such as rainfall, earthquake, etc.) would be necessary to reactivate the 343 landslide. 


\subsection{Landslide reactivation}

It has been reported that soil saturation due to the fast infiltration of rainfall is the main reason for the initiation of a huge number of shallow landslides (De Vita et al., 1998; Pasuto and Silvano, 1998; Polemio and Sdao, 1999; Hilley et al., 2004; Coe et al., 2004; Aleotti, 2004). For the landslides in reservoir area, fluctuation of the water level plays a key role in the initiation of instability of embankment slopes due to the change in water content and seepage conditions in the slope (Schuster, 1979; Pudasaini and Miller, 2012b). This can be exemplified by the Vaiont landslide in Italy (Genevois and Ghirotti, 2005), and also by the Qianjiangping landslide in the Three Gorges Reservoir (Wang et al., 2004).

For a landslide in the reservoir, the pore-water pressure of soils within the sliding zone changes following seasonal rainfall and periodic water level fluctuation, indicating the rise and fall of the underground water table respectively. The monitoring data of tensiometer and GPS has shown that dormant landslides in the Three Gorges Reservoir accelerated as

358 the underground water rose and decelerated as it fell (Wang et al., 2008; Yin et al, 2010). These conditions can be explained by using Mohr-Coulomb failure rule and Newton's second law of motion (Schulz et al, 2009b).

The variation of shear resistance of the sliding soil within the shear band can be expressed as $\tau_{f}(t)=c+\left\{\sigma-\left[u_{w}+p(z, t)\right]\right\} \tan \phi$, where $\tau_{f}(t)$ is the shear resistance of the

363 sliding soil within the shear band, and $p(z, t)$ is the pore pressure at distance $z$ (hear the 364 depth of the sliding mass above the sliding surface), which is the result of pore pressure 
365 diffusion due to the application of fluctuating reservoir water level and rainfall (Talwani 366 and Acree, 1984; Haneberg, 1991; Reid, 1994); $c$ and $\phi$ are the cohesion and internal 367 friction angle of soils within the sliding zone respectively; $\sigma$ and $u_{w}$ are the total normal 368 stress and pore-water pressure of the soils within the sliding zone respectively.

The above expression for $\tau_{f}(t)$ says that the changing of pore water pressure of the

370 sliding soil within the shear band will have a delayed time $t$, because the diffusion of

371 pore-water pressure in the landslide depends on the hydraulic conductivity, the thickness of

372 sliding mass and the externally applied load due to the fluctuation of the water level induced

373 by the landslide impact generated water waves in the reservoir (Pudasaini and Miller,

374 2012b). For the reactivation of dormant landslide in Jurassic red-strata in TGR, the soil

375 layer above sliding surface (or sliding mass) are mainly $6 \mathrm{~m}$ to $20 \mathrm{~m}$. As a result, the

376 response will be delayed more significantly. This may be the reason why the monitored

377 landslide displacement showed sharp increment often after the heavy rainfall or the water

378 level regulation of TGR.

Around 2490 landslides had been identified in the TGR area before the construction of

380 the dam, and great efforts had been paid to manage or monitor some large landslides at high

381 risk. However, more detailed survey since the impoundment of the reservoir revealed that

382 there are more than 5700 landslides (Liu et al., 2009), and many of them are reactivated

383 ones. Due to the financial limitation, engineering countermeasures had been performed only

384 on those landslides at high risk of catastrophic failure, while other dangerous landslides

385 could only be monitored. Therefore, understanding the reactivation and movement 
386

387

mechanisms of those seemingly dormant landslides is of great importance for the mitigation of landslide hazards in TGR area.

Cracks on the walls of houses or fissures on the ground on a slope had been normally regarded as the precursors of landslides. However, the appearance of cracks or fissures does not mean that sliding surface has been formed (Kamai, 1998). In this aspect, the monitored displacements summarized in Fig. $2 \mathrm{a}$ are consistent with the results obtained in other landslides (e.g., Suemine, 1983; Kamai, 1998; Petley et al., 2002), and may provide help for identifying whether the slope in Jurassic red-strata is at the failure-surface transmission state or has already entered the residual (sliding) state (Kamai, 1998). This is important for the stability analysis because the mobilized shear strengths at differing states will be different.

From Fig. 2b, we found that these slow moving landslides in Jurassic red-strata experienced movement with differing velocities. Although this kind of movement may result from many factors, such as rainfall and variation of water level in the reservoir, the variation of residual shear strength of the sample with shear rate may also play a key role in the movement. When the landsliding becomes faster, the shear resistance will become greater to decelerate the movement. Therefore, it is expected that these landslides will experience continuous accelerating-decelerating process, similar to the dynamics of a rainfall-triggered landslide in Japan reported by Wang et al. (2010).

It is well known that for the landslides in reservoir area, fluctuation of the water level plays a key role in the initiation of instability of embankment slopes due to the change in water content and seepage conditions in the slope. The change in interstitial fluid pressure is 
407

408

409

411

412

413

414

415

416

417

one of the most important material parameters determining the landslide initiation and the dynamics of the flow and the depositional characteristics. The flow pattern, flow mobility, runout distance, deposition morphology and energy dissipation are substantially influenced by the pore water pressure (Sassa 1988; Iverson and Denlinger, 2001; Pitman and Le, 2005; Pudasaini et al., 2005; Sassa and Wang, 2005; Pudasaini, 2012; Pudasaini and Miller, 2013). On the one hand, this means that the accurate knowledge of the pore fluid pressure is very crucial for the reliable predictions of the flow event and their dynamics. While on the other hand, the data obtained here can be utilized to validate landslide and mass flow models by back simulating the sliding mass, the fluid wave and dam walls interactions, submarine mass flows, their deposition fans and extents (Pudasaini and Miller, 2012b) in technically, geologically and environmentally more sensitive huge man made reservoirs and dams, including the 1963 Vaiont landslide (Genevois and Ghirotti, 2005), and the landslides in TGR in China. The model and unified simulation method proposed by Pudasaini and Miller (2012a, b) can be applied to adequately describe the change (fluctuation) of water level in the reservoir due to landslide impact at the reservoir. This is an important aspect, because it plays a key role in the initiation of instability of embankment slopes due to the change in water content and seepage conditions in the slope.

\section{Conclusions}

This paper presents the basic movement features of 21 landslides occurring in the Jurassic red-strata in TGR and discusses the landslide's slow moving behavior. Three 
428 groups of ring shear tests were performed to examine the possible mechanisms for different

429 types of landslide movements. Shear speed effect, residual shear strength recovery and

430 landslide reactivation trigger, are discussed to reveal the mechanisms of the slow-moving

431 landslides in Jurassic red-strata in TGR. We draw the following conclusions.

(1) The movement of the landslide in Jurassic red-strata in the TGR before the catastrophic failure can be divided into two differing states, i.e., the slow movement with different sliding rates, and the creep movement due to the crack propagation.

(2) The residual shear strength is positively dependent on the shear rate. This may be one of the main reasons for the decelerating movement resulting in the cease of landsliding.

Further, the residual shear strength of the soils within the sliding zone could have a certain recovery in a short time. This will elevate the stability of the landslides in Jurassic red-strata in TGR. This makes the reactivation of the landslide less likely.

(3) The landslides in Jurassic red-strata in TGR display a delayed response to the

441 rainfall and/or periodic fluctuation of reservoir water level. This delay depends on the 442 permeability, the thickness of landsliding mass, and also the externally applied load due to 443 the fluctuation of the water level induced by the landslide impact generated water waves in 444 the reservoir.

\section{Acknowledgements}

447 This study was supported by the National Natural Science Foundation of China (No. 448 41101515, No. 41202247 and No. 41240023). Also this study was partially supported by 
449 the Fundamental Research Funds for the Central Universities, China University of 450 Geosciences (Wuhan), No. CUGL110203. The authors thank Wei Wang, Xiawei Yi, Jiang $451 \mathrm{Wu}$ and Yingchun Li for the works in the field investigation and sample collecting. The first 452 author would like to thank Dr. Hiroshi Fukuoka, Associate Professor in Disaster Prevention 453 Research Institute, Kyoto University, for his help when the first author was staying in Kyoto 454 University for this joint research. Finally, the authors' special thanks go to the editor and 455 referees of this paper; whose valuable comments led to substantial improvement of this 456 paper.

457

\section{References}

459 Aleotti, P., 2004. A warning system for rainfall-induced shallow failures. Engineering $460 \quad$ Geology 73(3-4), 247-265.

461 Bishop, A.W., Green, G.E., Garga, V.K., Andresen, A., Brown, J.D., 1971. A new ring shear apparatus and its application to the measurement of residual strength. Géotechnique 21(4), 273-328.

464 Bromhead, E.N., 1979. A simple ring shear apparatus. Ground Engineering 12(5), 40-44.

465 Bromhead, E.N., 1992. Stability of slopes, 2nd Ed., Surrey University Press, London.

466 Carrubba, P., Del Fabbro, M., 2008. Laboratory investigation on reactivated residual 467 strength. Journal of Geotechnical and Geoenvironmental Engineering 134(3), 302-315. 
468 Chai, B., Yin, K.L., Jian, W.X., Dai, Y.X., 2009. Analysis of water-rock interaction 469 characteristics and bank slope failure process of red-strata. Journal of Central South $470 \quad$ University (Science and Technology), 40(4), 1092-1098 (in Chinese).

471 Chen, D.J., 1999. Engineering geological problems in the Three Gorges Project on the Yangtze, China. Engineering Geology 51(3), 183-193.

473 Chen, Q., Kou X.B., Huang, S.B., Zhou, Y.J., 2004. The distributes and geologic 474 environment characteristics of red beds in China. Journal of Engineering Geology 12(1), 34-40 (in Chinese).

476

477

478

Coe, J.A., Michael, J.A., Crovelli, R.A., Savage, W.Z., Lappade, W.T., Nashem, W.D., 2004. Probabilistic assessment of precipitation-triggered landslides using historical records of landslide occurrence, Seattle, Washington. Environmental and Engineering Geoscience 10(2), 103-122.

De Vita, P., Reichenbach, P., Bathurst, J.C., Borga, M., Crosta, G., Crozier, M., Glade, T., Guzzetti, F., Hansen, A., Wasowski, J., 1998. Rainfall-triggered landslides: a reference list. Environmental Geology 35(2-3), 219-233.

Deng, Q.L., Zhu, Z.Y., Cui, Z.Q., Wang, X.P., 2000.Mass rock creep and landsliding on the Huangtupo slope in the reservoir area of the Three Gorges Project, Yangtze River, China. Engineering Geology 58(1), 67-83.

Genevois, R., Ghirotti, M., 2005. The 1963 Vaiont landslide. Giornale di Geologia Applicata 1, 41-52. 
488 Gibo, S., Egashira, K., Ohtsubo, M., 2002. Strength recovery from residual states in reactivated landslides. Géotechnique 52(9), 683-686.

Haneberg, W.C., 1991. Pore-pressure diffusion and the hydrologic response of nearly saturated, thin landslide deposits to rainfall. The Journal of Geology 99(6), 886-892.

Harris, A.J., Watson, P.D.J., 1997. Optimal procedure for the ring shear test. Ground Engineering 30(6), 26-28.

494

Hilley, G.E., Burgmann, R., Ferretti, A., Novali, F., Rocca, F., 2004. Dynamics of slow-moving landslides from permanent scatterer analysis. Science 304, 1952-1955.

Huang, R.H., 2007. Large-scale landslides and their sliding mechanisms in China since the $20^{\text {th }}$ century. Chinese Journal of Rock Mechanics and Engineering 26(3), 434-454 (in Chinese)

Hungr, O., Morgenstern, N.R., 1984. Ring velocity ring shear tests on sand. Géotechnique 34(3), 415-421.

501 Iverson, R.M., Denlinger, R.P., 2001. Flow of variably fluidized granular masses across three-dimensional terrain: 1. Coulomb mixture theory. Journal of Geophysical Research: Solid Earth (1978-2012), 106(B1): 537-552.

504 Jian, W.X., Yin, K.L., Ma, C.Q., Liu, L.L., Zhang C., 2005. Characteristics of incompetent 505 beds in Jurassic red clastic rocks in Wanzhou. Rock and Soil Mechanism 26(6), 901-905 (in Chinese). 
507 Jian, W.X., Yin, K.L., Luo, C., Yao, L.L., Zhang, C., 2008. Slip zone characteristics of 508 Anlesi landslide in Wanzhou of Three Gorges Reservoir area. Earth science - Journal 509 of China University of Geosciences 33(5), 672-678 (in Chinese).

510 Jian, W.X., Wang, Z.J., Yin, K.L., 2009. Mechanism of the Anlesi landslide in the Three 511 Gorges Reservoir, China. Engineering Geology 108(1-2), 86-95.

512 Kamai, T., 1998. Monitoring the process of ground failure in repeated landslides and 513 associated stability assessments. Engineering Geology 50(1-2), 71-84.

514 Lemos, L.J.L., Skempton, A.W., Vaughan, P.R., 1985. Earthquake loading of shear surfaces in slopes. In proceedings of 11th International Conference on Soil Mechanics and Foundation Engineering, 1955-1958.

Lemos, L.J.L., 1986. The effect of rate on residual strength of soil. Ph.D. Thesis, Imperial Collage London (University of London).

Li, L.R., 2002. Geological hazards and prevention in the Three Gorges dam area. Land and Resources 4, 4-7.

Li, T.Y., Wang, J.L., 2002. Chinese red beds and landforms. Journal of Sichuan Normal University (Natural Science) 25(4), 427-431 (in Chinese).

Li, Y.R., Wen, B.P., Aydin, A., Ju, N.P., 2013. Ring shear tests on slip zone soils of three giant landslides in the Three Gorges Project area. Engineering Geology 154, 106-115.

Liao, Q.L., Li, X., Li, S.D., Dong Y.H., 2005. Occurrence, geology and geomorphy characteristics and origin of Qiangjiangping landslide in Three Gorges Reservoir area 
and study on ancient landslide criterion. Chinese Journal of Rock Mechanics and Engineering 24(17), 3146-3153 (in Chinese).

Liu, C.Z., Liu Y.H., Wen, M.S., Li, T.F., Lian, J.F., Qin, S.W., 2009. Geo-hazard initiation and assessment in the Three Gorges Reservoir. In: Landslide Disaster Mitigation in Three Gorges Reservoir, China (Wang and Li, eds). Springer, pp.3-40.

Liu, J.G., Mason, P.J., Clerici, N., Chen, S., Davis, A., Miao, F., Deng, H., Liang, L., 2004. Landslide hazard assessment in the Three Gorges area of the Yangtze River using ASTER imagery: Zigui-Badong. Geomorphology 61(1-2), 171-187.

Lupini, J.F., 1980. The residual strength of soils. Ph.D. Thesis, Imperial Collage London (University of London).

Lupini, J.F., Skinner, A.E., Vaughan, P.R., 1981. The drained residual strength of cohesive soils. Géotechnique 31(2), 181-213.

Martins, J.P., 1982. Shaft resistance of axially loaded piles in clay. Géotechnique 32(4), 369-384.

Mitchell, J.K., 1976. Fundamentals of soil behavior. New York: John Wiley and Sons, Inc.

Nakamura, S., 2002. Studies on residual strength and strength recovery from residual state for landslide soils. Science Bulletin of the Faculty of Agriculture, University of the Ryukyus, 49: 97-142 (in Japanese with English abstract).

545 Pasuto, A., Silvano, S., 1998. Rainfall as a trigger of shallow mass movements. A case study in the Dolomites, Italy. Environment Geology 35(2-3), 184-189. 
547 Petley, D.N., Bulmer, M.H., Murphy, W., 2002. Patterns of movement in rotational and $548 \quad$ translational landslides. Geology 30(8), 719-722.

549 Petley, D.N., Mantovani, F., Bulmer, M.H., Zannoni, A., 2005. The use of surface 550 monitoring data for the interpretation of landslide movement patterns. Geomorphology $551 \quad 66(1-4), 133-147$.

552 Pitman, E.B., Le, L., 2005. A two-fluid model for avalanche and debris flows. Philosophical 553 Sciences 363(1832), 1573-1601.

Polemio, M., Sdao, F., 1999. The role of rainfall in the landslide hazard: the case of the Avigliano urban area (Southern Apennines, Italy). Engineering Geology 53(3-4), 297-309.

Pudasaini, S.P., 2012. A general two-phase debris flow model. Journal of Geophysical Research: Earth Surface (2003-2012), 117(F3), doi:10.1029/2011JF002186.

Pudasaini, S.P., Wang, Y., Hutter, K., 2005. Modelling debris flows down general channels. Natural Hazards and Earth System Science 5(6), 799-819.

562 Pudasaini, S.P., Hutter, K., 2007. Avalanche dynamics: dynamics of rapid flows of dense 563 granular avalanches, Springer, Berlin, New York.

564 Pudasaini, S.P., Miller, S.A., 2012a. Buoyancy induced mobility in two-phase debris flow. AIP Conference Proceedings-American Institute of Physics, 1479(1): 149-152.

566 Pudasaini, S.P., Miller, S.A., 2012b. A real two-phase submarine debris flow and tsunami. AIP Conference Proceedings-American Institute of Physics, 1479(1): 197-200. 
568 Pudasaini, S.P., Miller, S.A., 2013. The hypermobility of huge landslides and avalanches. Engineering Geology, 157: 124-132.

Reid, M.E., 1994. A pore-pressure diffusion model for estimating landslide-inducing rainfall. The Journal of Geology 102(6), 709-717.

Ren, G.M., Nie, D.X., Zuo, S.S., 1996. Study on cohesion restoration of slide zone soil. Journal of Geological Hazards and Environment Preservation 7(3), 7-12 (in Chinese).

Sadrekarimi, A., Olson, S.M., 2009. A new ring shear device to measure the large displacement shearing behavior of sands. ASTM Geotechnical Testing Journal 32(3), 197-208.

Sassa, K., 1988. Special lecture: the geotechnical model for the motion of landslides. Proceedings of the $5^{\text {th }}$ International Symposium on Landslides, Lausanne, vol.1, 33-52.

Sassa, K., Wang, G., Fukuoka, H., 2003. Performing undrained shear tests on saturated sands in a new intelligent type of ring shear apparatus. ASTM Geotechnical Testing Journal, 26(3): 257-265.

Sassa, K., Fukuoka, H., Wang, G.H., Ishikaka, N., 2004. Undrained dynamic-loading ring-shear apparatus and its application to landslide dynamics. Landslides, 1(1): 7-19.

Sassa, K., Wang, G.H., 2005. Mechanism of landslide-triggered debris flows: Liquefaction phenomena due to the undrained loading of torrent deposits. In Debris-flow hazards and related phenomena (pp. 81-104). Springer Berlin Heidelberg. triggered by atmospheric tides. Nature Geoscience 2(12), 863-866. 
589 Schulz, W.H., McKenna, J.P., Kibler, J.D., Biavati, G., 2009b. Relations between 590 hydrology and velocity of a continuously landslide - evidence of pore-water pressure 591 feedback regulating landslide motion? Landslides 6(3), 811-190.

592 Schuster, R.L., 1979. Reservoir-induced landslides. Bulletin of the International Association 593 of Engineering Geology 20(1), 8-15.

594 Schuster, R.L., Krizek, R. (Editors), 1979. Landslides: analysis and control. Transportation 595 Research Board, National Academy of Sciences, Washington, D.C., Special Report 596 $176,234 \mathrm{pp}$

Skempton, A.W., 1985. Residual strength of clays in landslides folded strata and the laboratory. Géotechnique 35(1), 1-18.

Stark, T.D., Contreras, I.A., 1996. Constant volume ring shear apparatus. ASTM Geotechnical Testing Journal 19(1), 3-11.

601 Suemine, A., 1983. Study on landslide mechanism in the area of crystalline schist (part 602 603 Research Institute of Kyoto University 33 (3), 105-127.

604 Suzuki, M., Kobayashi, K., Yamamoto, T., Matsubara, T., Hukuda, J., 2004. Influence of 605 606 shear rate on residual strength of clay in ring shear test. Research Report, School of Engineering, Yamaguchi University 55(2), 49-62.

607 Talwani, P. and Acree, S., 1984. Pore pressure diffusion and the mechanism of 608 reservoir-induced seismicity. Pure and Applied Geophysics 122(6), 947-965. 
609

610

611

612

613

614

615

616

617

618

619

620

621

622

623

624

625

626

627

628

Tika, T.E., 1989. The effect of fast shearing on the residual strength of soils. Ph.D. Thesis, Imperial Collage London (University of London).

Tika, T.E., Vaughan, P.R., Lemos, L.J.L., 1996. Fast shearing of pre-existing shear zone in soil. Géotechnique 42(2), 197-233.

Tiwari, B., Marui, H., 2004. Objective oriented multistage ring shear test for shear strength of landslide soil. Journal of Geotechnical and Geoenvironmental Engineering 130(2), 217-222.

Ueno, M., Itani, K., Langley, R. B., 2003. Real-time GPS landslide monitoring under poor satellite visibility. In Proceedings of 2003 International Symposium on GPS/GNSS, Tokyo, Japan, pp. 15-18.

Wang, F.W., Zhang, Y.M., Huo, Z.T., Matsumoto, T., Huang B.L., 2004. The July 14, 2003 Qiangjiangping landslide, Three Gorges Resrvoir, China. Landslides 1(2), 157-162.

Wang, F.W., Zhang, Y.M., Huo, Z.T., Peng, X.M., Araiba, K., Wang, G.H., 2008. The July 14, 2003 Movement of the Shuping landslide in the first four years after the initial impoundment of the Three Gorges Dam Reservoir, China. Landslides 5(3), 321-329.

Wang, G.H., Sassa, K., 2002. Post-failure mobility of saturated sands in undrained load-controlled ring shear tests. Canadian Geotechnical Journal 39(4), 821-837.

Wang, G.H., Sassa, K., Fukuoka, H., Tada, T., 2007. Experimental study on the shearing behavior of saturated silty soils based on ring-shear tests. Journal of Geotechnical and Geoenvironmental Engineering 133(3), 319-333. 
629 Wang, G.H., Suemine, A., Schulz, W.H., 2010. Shear-rate-dependent strength control on

630 the dynamics of rainfall-triggered landslides, Tokushima Prefecture, Japan. Earth

$631 \quad$ Surface Processes and Landforms 35(4), 407-416.

632 Wen, B.P, Aydin, A., Duzgoren-Aydin, N. S., Li, Y.R., Chen, H.Y., Xiao, S.D., 2007.

633 Residual strength of slip zones of large landslides in the Three Gorges area, China.

$634 \quad$ Engineering Geology 93(3-4), 82-98.

635 Wu, S.R., Shi, L., Wang, R.J., Tan, C.X., Hu, D.G., Mei, Y.T., Xu R.C., 2001. Zonation of

636 the landslide hazards in the forereservoir region of the Three Gorges Project on the

637 Yangtze River. Engineering Geology 59(1-2), 51-58

638 Xu, R.C., Zhou, J.J., 2010. Red bed and dam. Wuhan: China University of Geosciences

639 Press, second edition, 10-20 (in Chinese)

640 Yin, K.L., Wu, Y.P., 1998. Systematic research of one special paleo-landslide in the

641 Three-Gorges Reservoir. The Chinese Journal of Geological Hazard and Control, 9(S):

642 200-206 (in Chinese).

643 Yin, Y.P., Wang, H.D., Gao, Y.L., Li, X., 2010. Real-time monitoring and early warning of 644 landslides at relocated Wushan Town, the Gorges Resrvoir, China. Landslides 7(3), 645 339-349. 


\section{Captions:}

Fig. 1. Location of the Three Gorges Reservoir in China.

Fig. 2. Curves of maximum accumulated displacement with time for 21 typical landslides in Jurassic red-strata in the Three Gorges Reservoir. (a) Maximum accumulated displacement is smaller than $100 \mathrm{~mm}$; (b) maximum accumulated displacement is larger than $100 \mathrm{~mm}$.

Fig. 3. Conceptual model for the slow movement of landslides in Jurassic red-strata in the Three Gorges Reservoir before their catastrophic failure. (a) Accumulated displacement versus time; (b) Displacement rate versus time.

Fig. 4. Xiangshanlu landslide (with a yellow asterisk mark), nearby Qianjiangping landslide, which occurred in the early morning on July 14, 2003 and caused 24 people died (Wang, et al., 2004; Liao, et al., 2005). (Image from Google Earth) (a):Location of the landslide in TGR; (b) details of landslide locations marked on Google Earth image.

Fig. 5. Xiangshanlu landslide. (a) Houses destroyed in the toe of the landslide; (b) sliding mass; (c) soils within the sliding zone; (d) thickness of the soils within the sliding zone; and (e) profile of the sliding mass.

Fig. 6. Indices of physical properties of soil sample from Xiangshanlu landslide (XSL sample). (a) Grain size distribution of sample XSL; (b) plasticity chart of XSL sample. 
Fig. 7. Ring shear test on the XSL sample. (a) Undrained shear behavior with the normal stress of $98 \mathrm{kPa}$; (b) residual shear strengths at different normal stresses.

Fig. 8. Ring shear test on the XSL sample at different shear speeds under the normal stress of $196 \mathrm{kPa}$.

Fig. 9. Ring shear test on the XSL sample with the different consolidation duration under the normal stress of $196 \mathrm{kPa}$. (a) shear resistance vs. shear displacement; and (b) vertical displacement vs. shear displacement.

Fig. 10. Configuration in the test of changing the pore-water pressure of shear zone.

Fig. 11. Shear behaviour of the sample XSL in the test of changing the pore-water pressure of shear band. (a) Shear stress and pore-water pressure versus time; (b) effective normal stress path in the test. 
Table 1. Basic physical properties index of the soils within the sliding zone of Xiangshanlu landslide

\begin{tabular}{lllllll}
\hline Physical properties index & $\rho_{d} / \mathrm{g} / \mathrm{cm}^{3}$ & $w_{L} / \%$ & $w_{P} / \%$ & $I_{P}$ & $C_{u}$ & $C_{c}$ \\
\hline XSL & 1.75 & 49.50 & 27.70 & 21.80 & 24.13 & 57.44 \\
\hline
\end{tabular}

Note: XSL, short for the sample collected from the sliding zone of Xiangshanlu landslide;

$\rho_{d}$ : dry density; $w_{L}$ : liquid limit; $w_{P}$ : plastic limit; $I_{P}$ : plastic index; $C_{u}$ : uniformity coefficient;

$C_{c}$ : coefficient of curvature. 


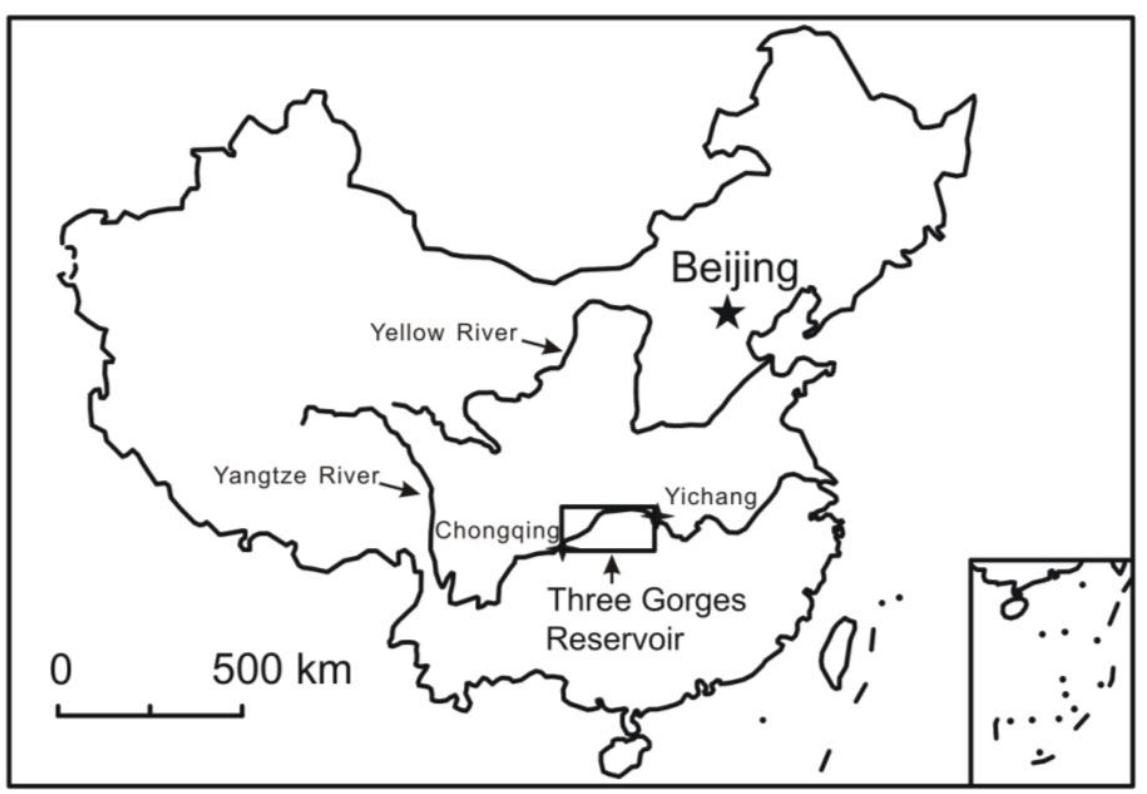

Fig. 1. Location of the Three Gorges Reservoir in China. 

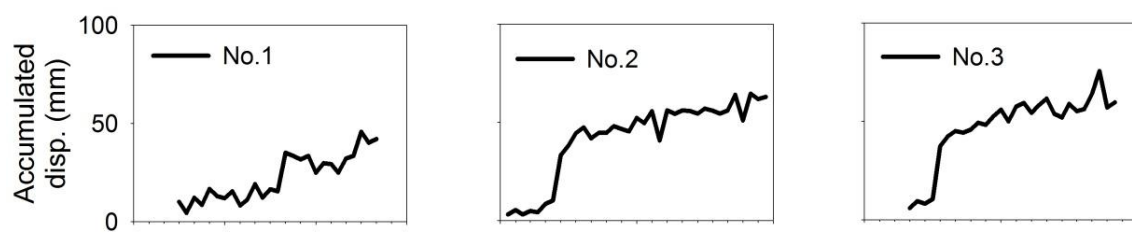

(a)
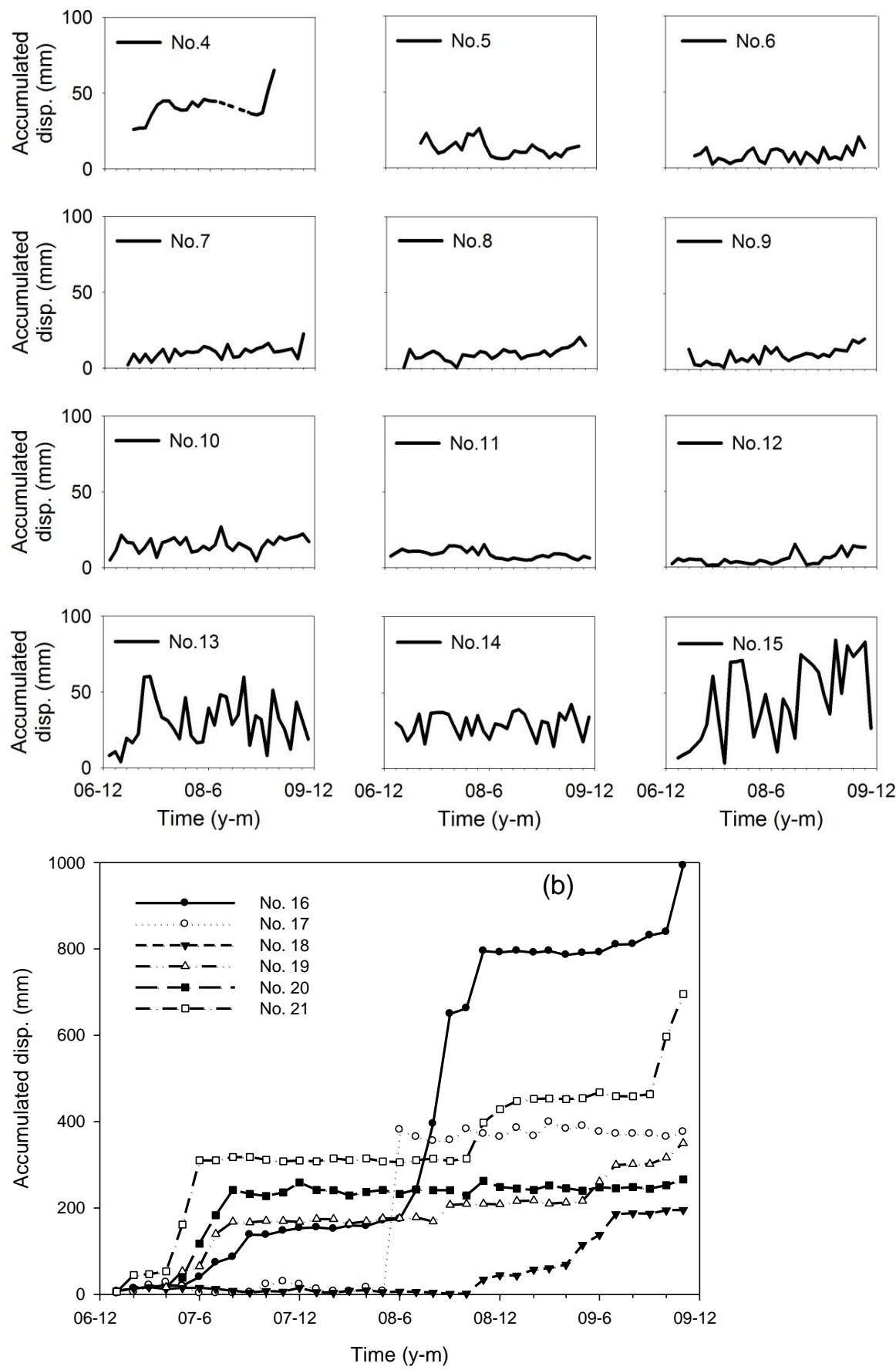

Fig. 2. Curves of maximum accumulated displacement with time for 21 typical landslides in Jurassic red-strata in the Three Gorges Reservoir. (a) Maximum accumulated displacement is smaller than $100 \mathrm{~mm}$; (b) maximum accumulated displacement is larger than $100 \mathrm{~mm}$. 

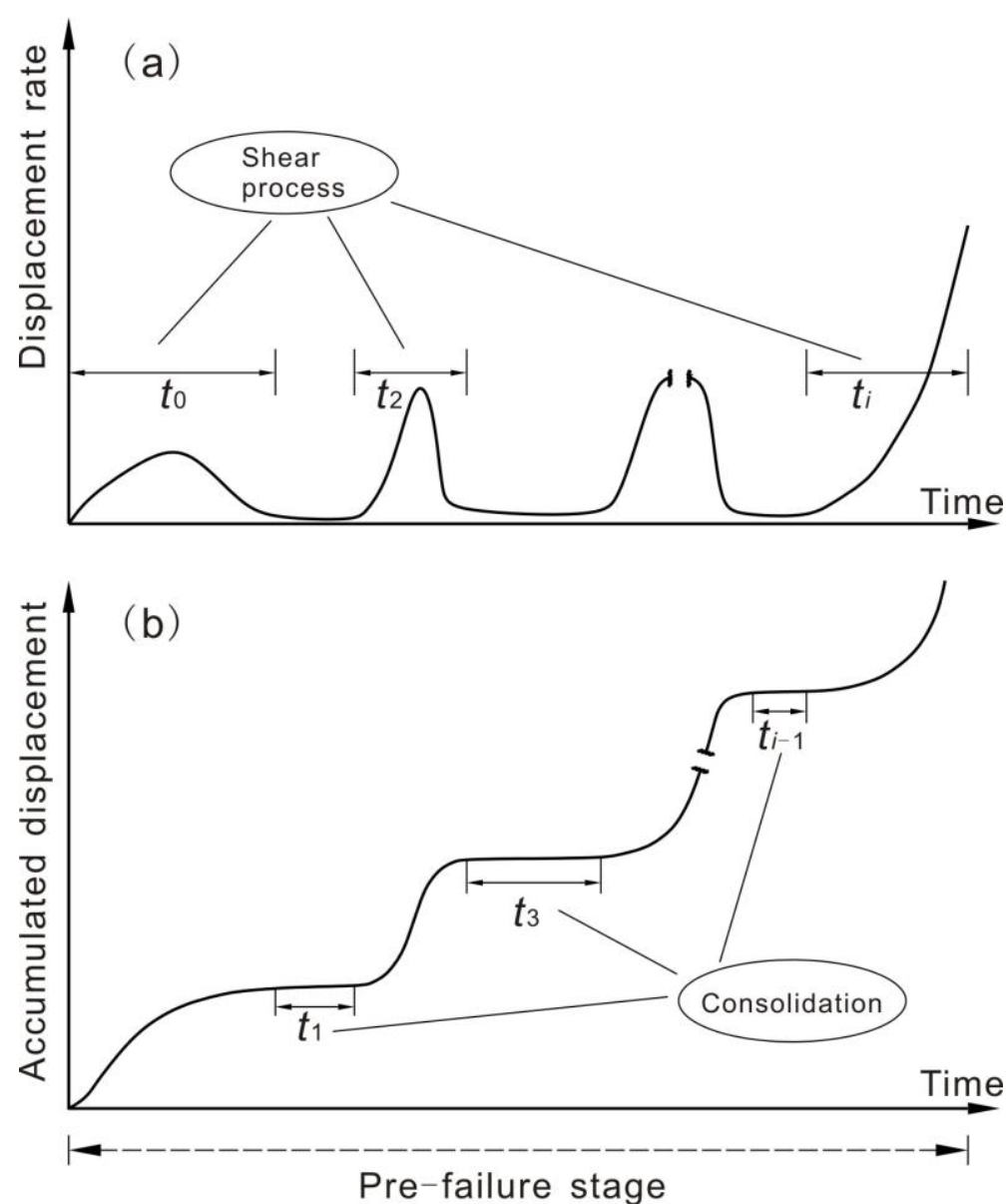

Fig. 3. Conceptual model for the slow movement of landslides in Jurassic red-strata in the

Three Gorges Reservoir before their catastrophic failure. (a) Accumulated displacement versus time; (b) Displacement rate versus time. 

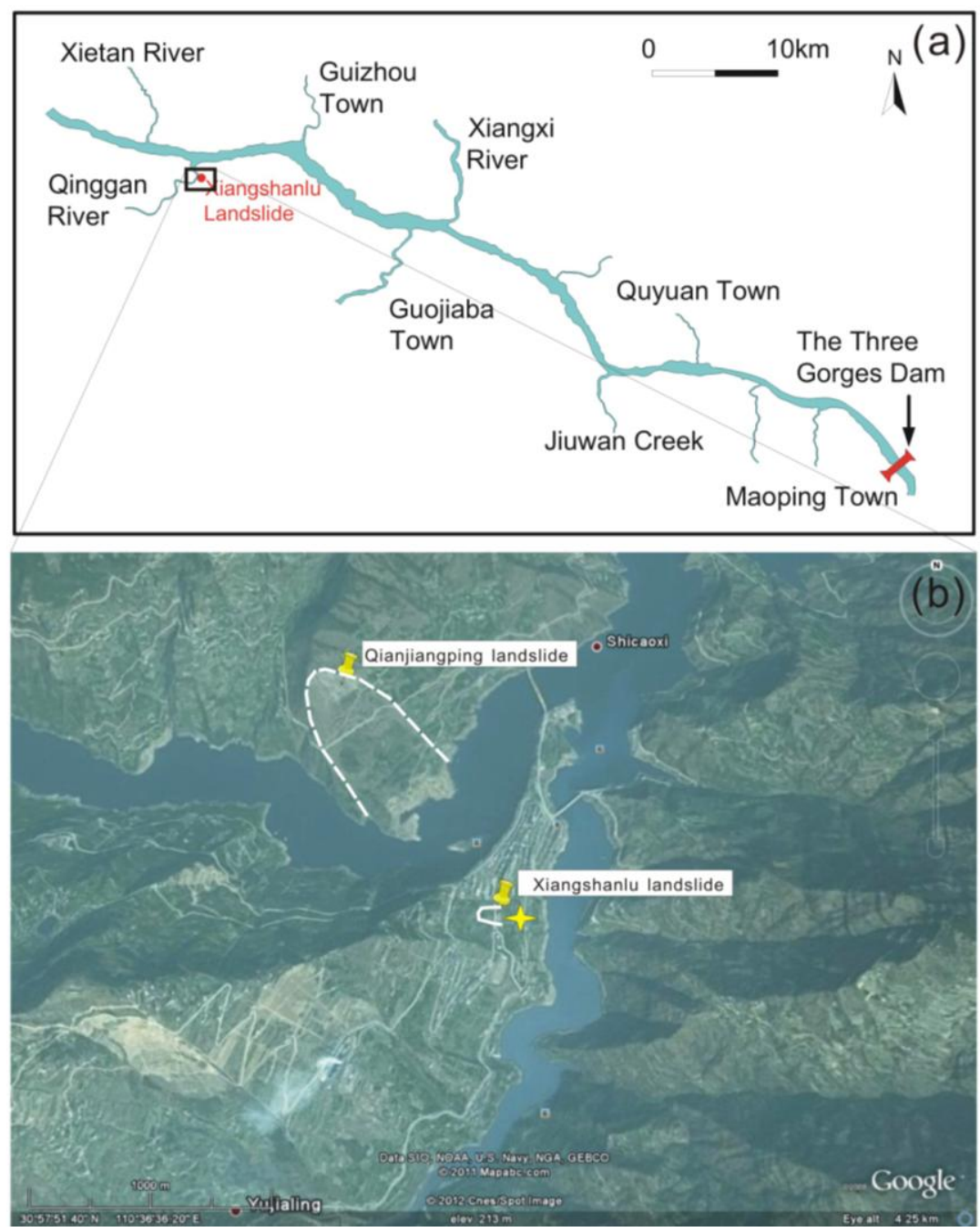

Fig. 4. Xiangshanlu landslide (with a yellow asterisk mark), nearby Qianjiangping landslide, which occurred in the early morning on July 14, 2003 and caused 24 people died (Wang, et al., 2004; Liao, et al., 2005). (Image from Google Earth) (a):Location of the landslide in TGR; (b) details of landslide locations marked on Google Earth image. 

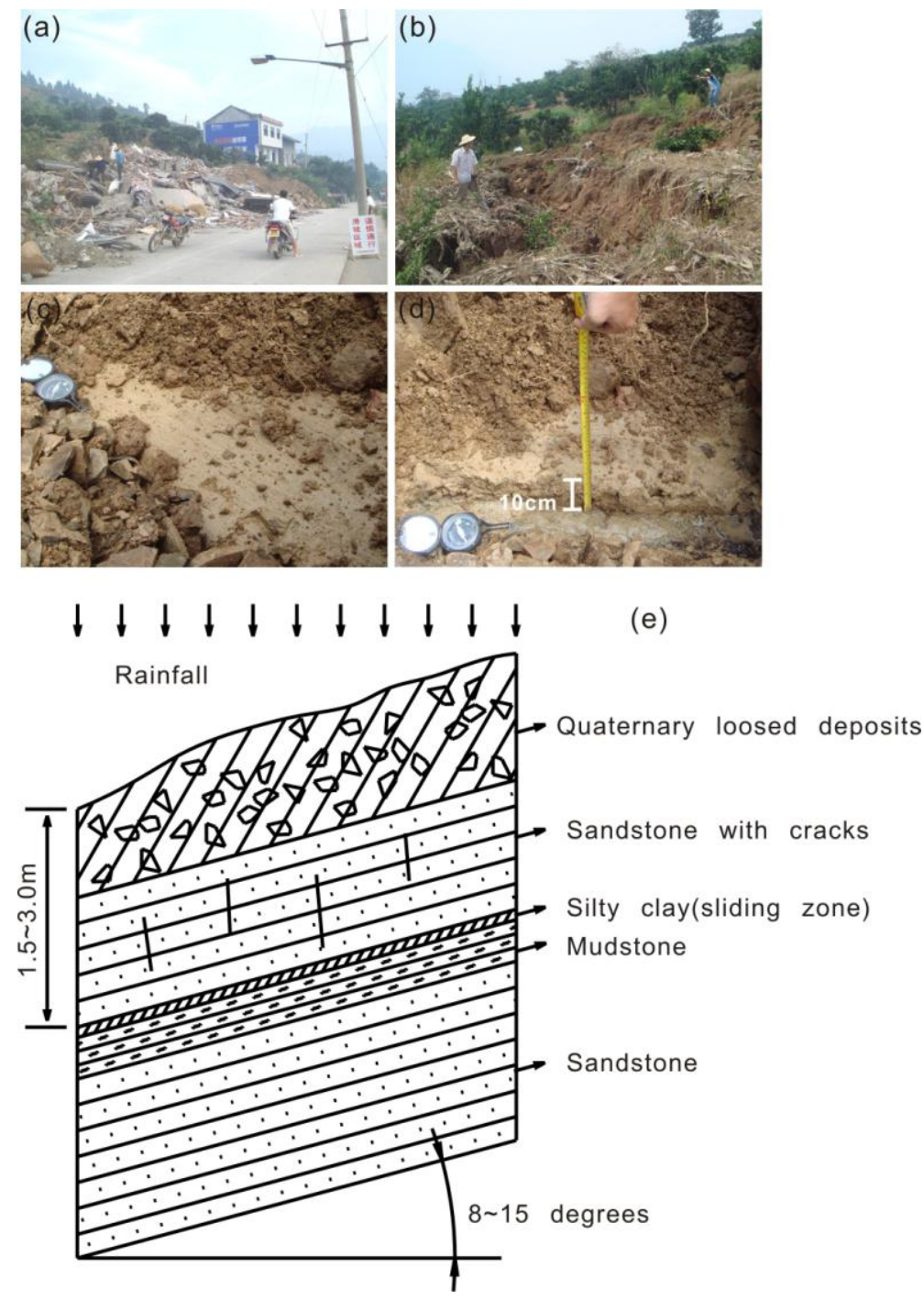

Fig. 5. Xiangshanlu landslide. (a) Houses destroyed in the toe of the landslide; (b) sliding mass; (c) soils within the sliding zone; (d) thickness of the soils within the sliding zone; and (e) profile of the sliding mass. 

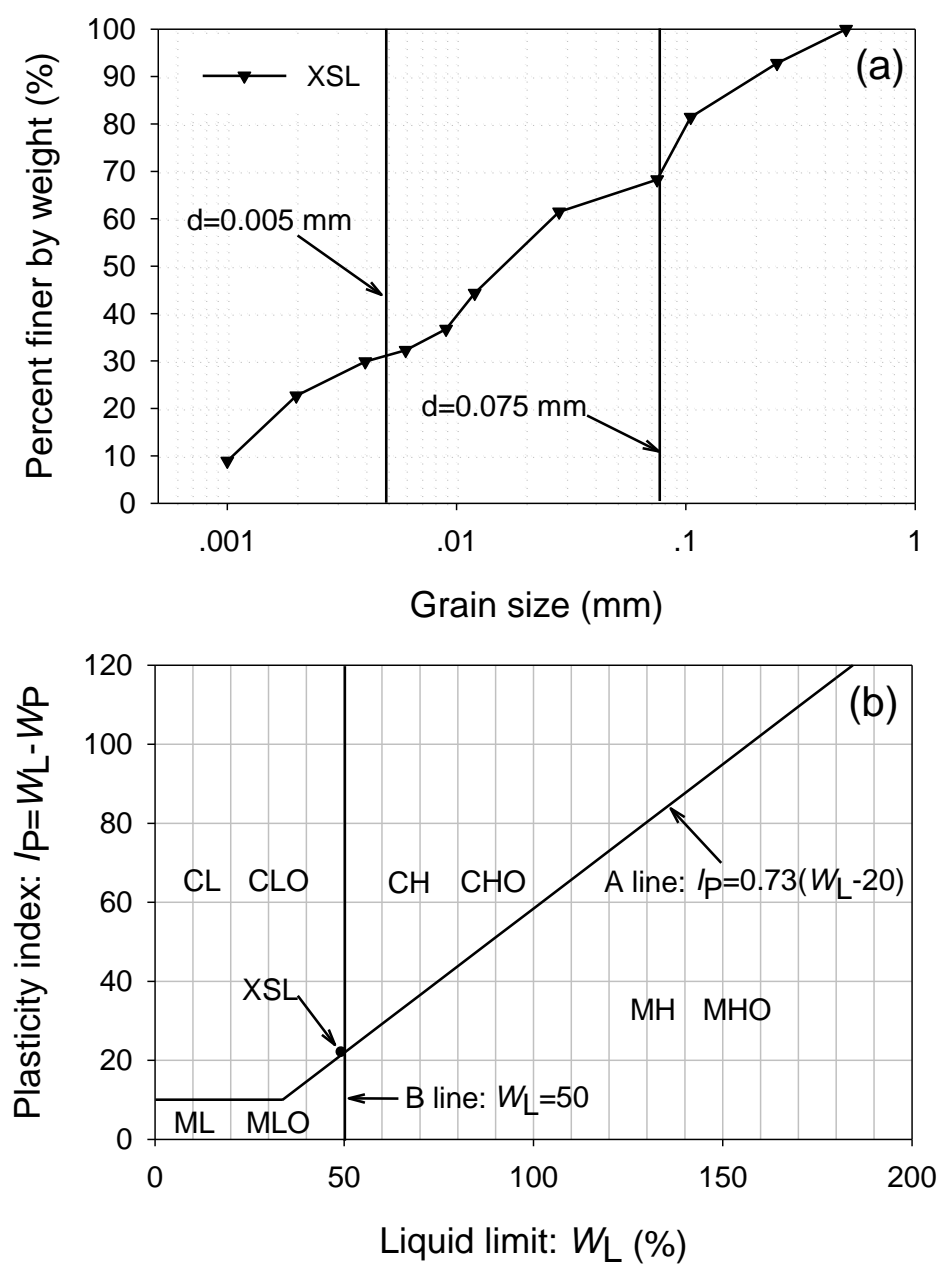

Fig. 6. Indices of physical properties of soil sample from Xiangshanlu landslide (XSL sample). (a) Grain size distribution of sample XSL; (b) plasticity chart of XSL sample. 

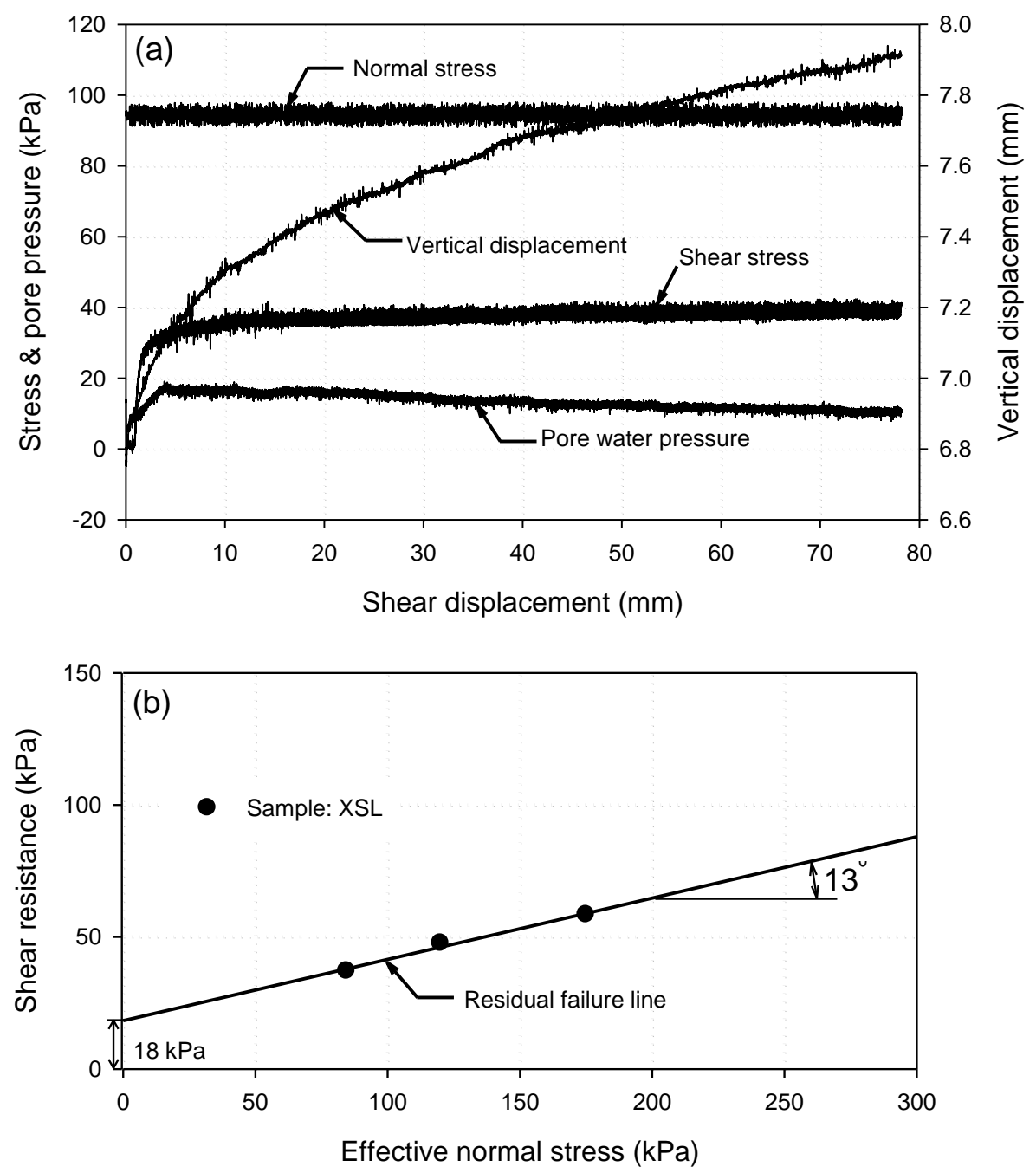

Fig. 7. Ring shear test on the XSL sample. (a) Undrained shear behavior with the normal stress of $98 \mathrm{kPa}$; (b) residual shear strengths at different normal stresses. 


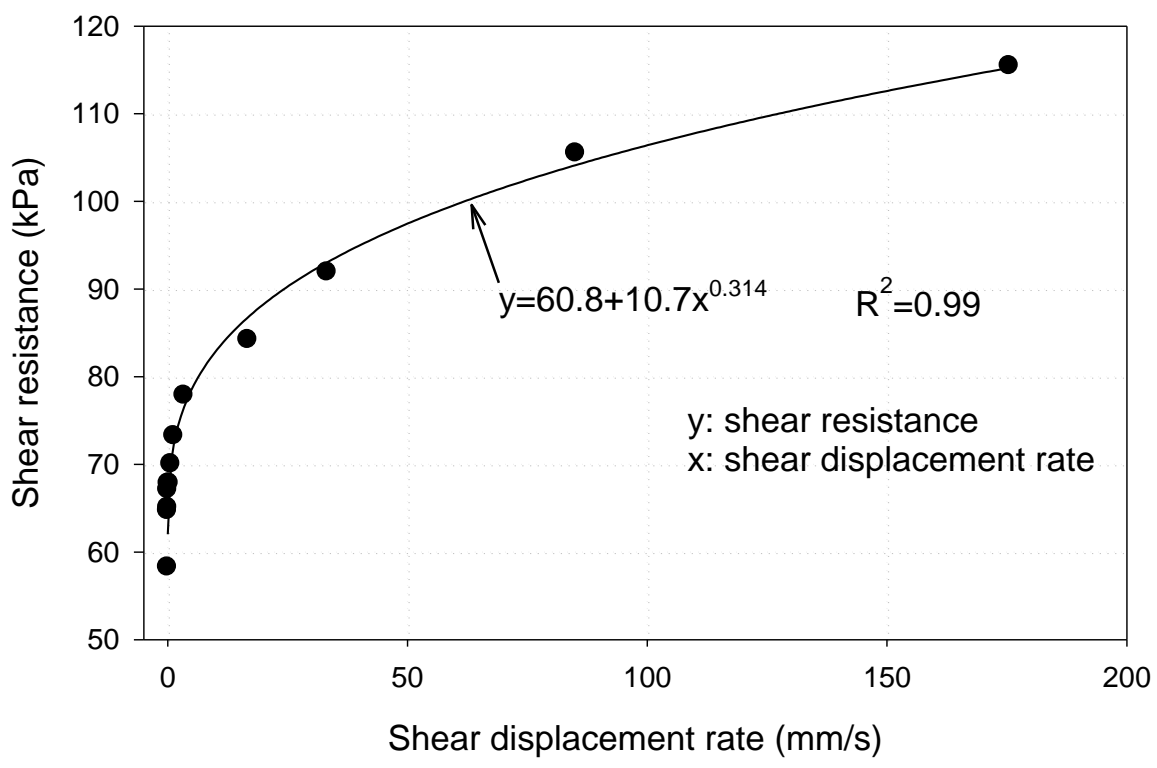

Fig. 8. Ring shear test on the XSL sample at different shear speeds under the normal stress of $196 \mathrm{kPa}$. 

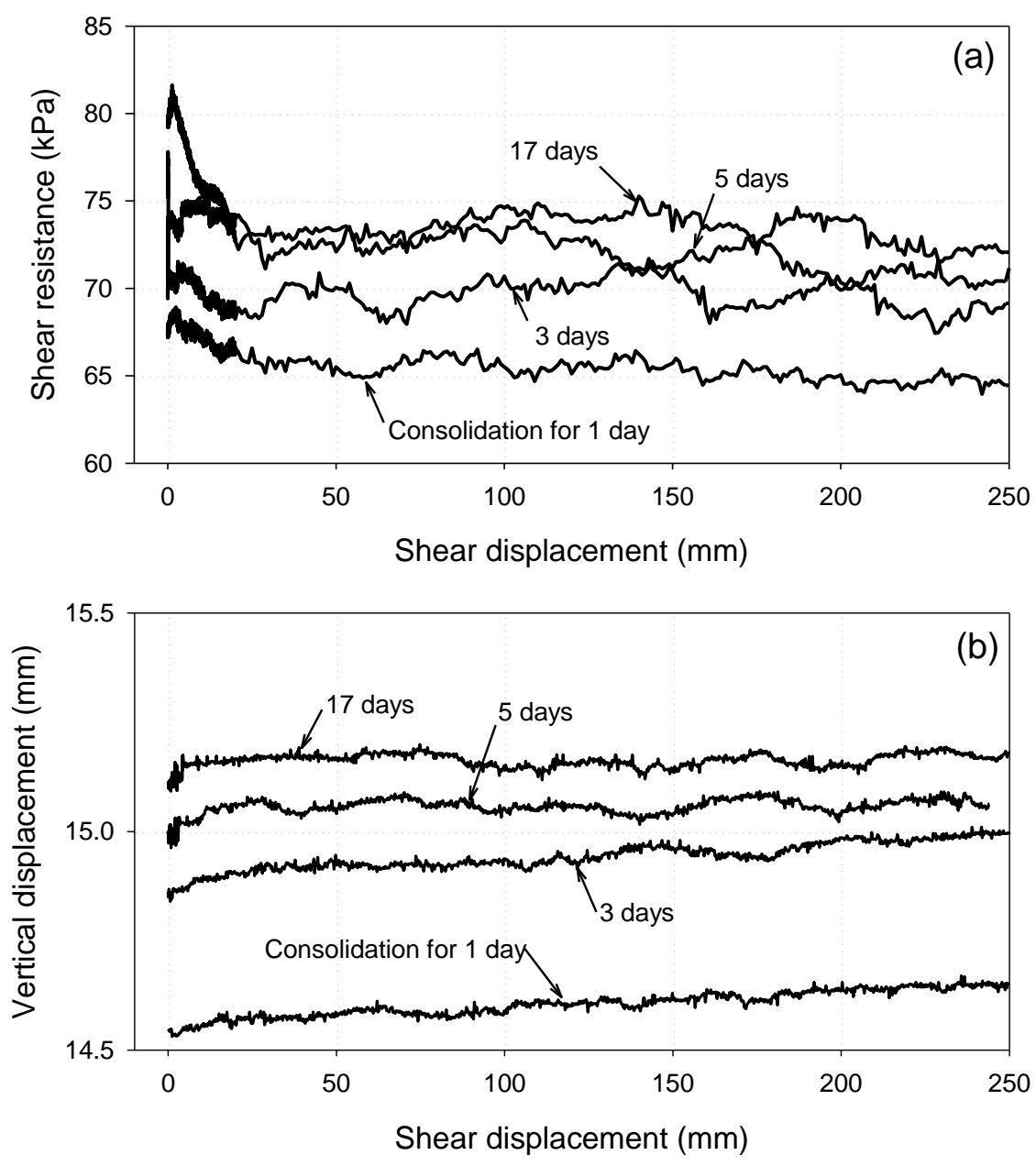

Fig. 9. Ring shear test on the XSL sample with the different consolidation duration under the normal stress of $196 \mathrm{kPa}$. (a) shear resistance vs. shear displacement; and (b) vertical displacement vs. shear displacement. 


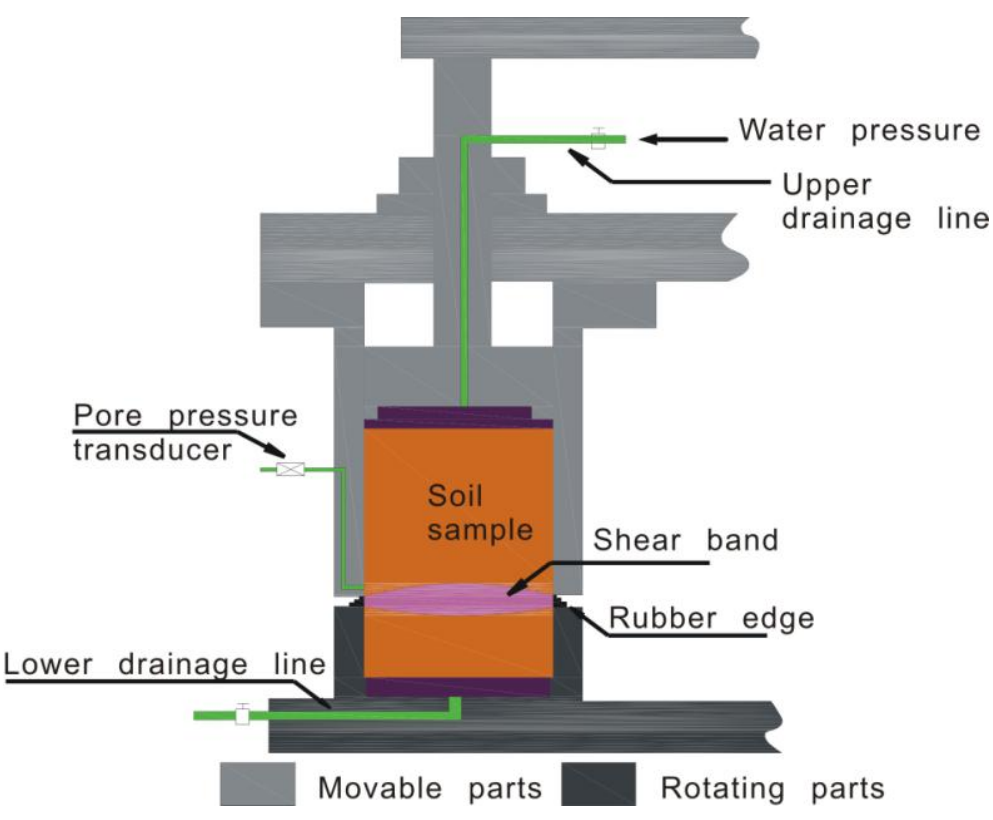

Fig. 10. Configuration in the test of changing the pore-water pressure of shear band. 

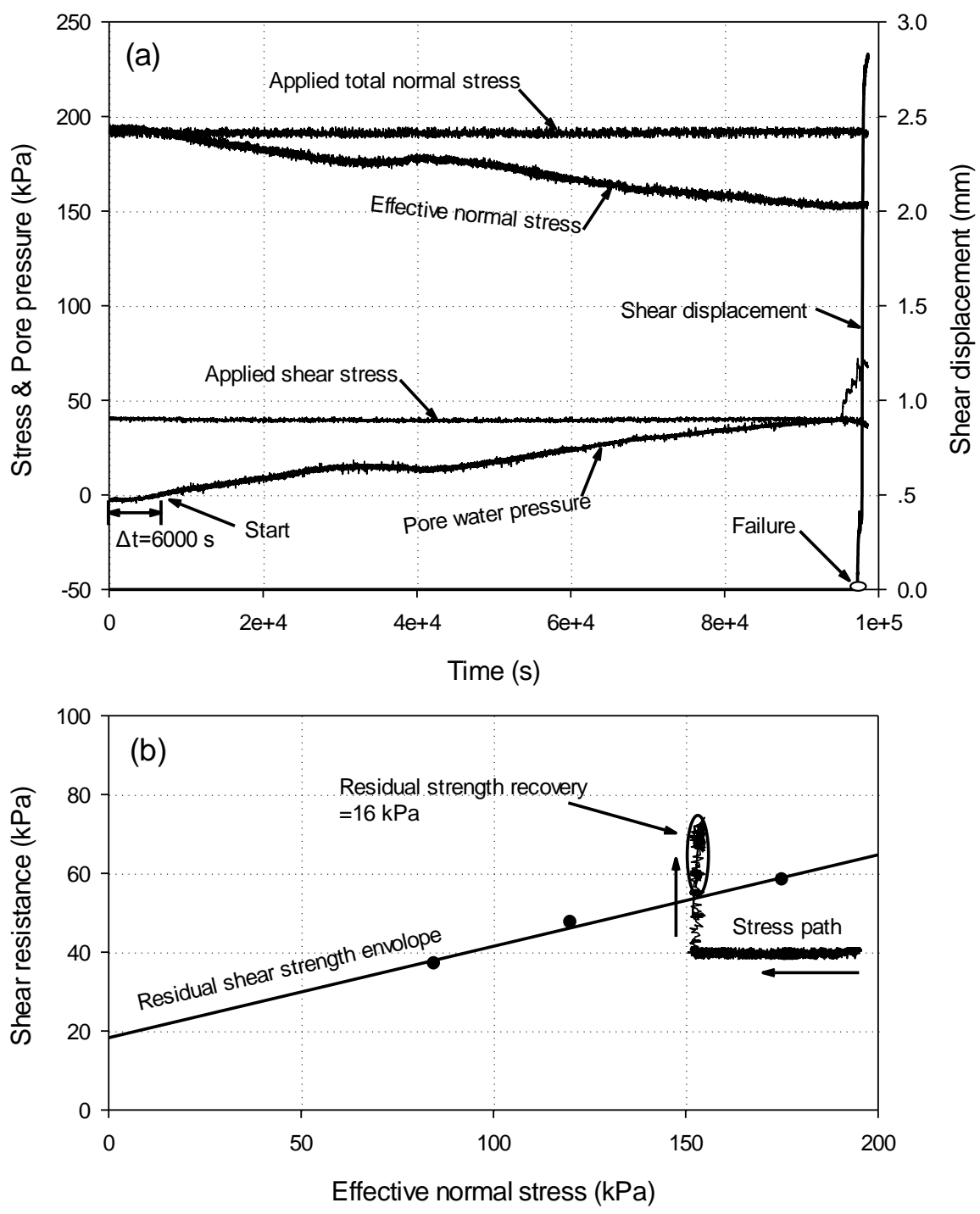

Fig. 11. Shear beheavoir of the sample XSL in the test of changing the pore-water pressure of shear band. (a) Shear stress and pore-water pressure versus time; (b) effective normal stress path in the test. 